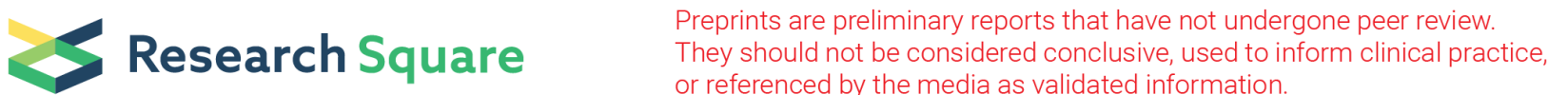 \\ Interface Induced Diffusion; Area Selective Interface Patterning
}

\section{S Gurbán}

Institute for Technical Physics and Materials Science, Centre for Energy Research, P.O.B. 49, H-1525

Budapest, Hungary

\section{A Sulyok}

Institute for Technical Physics and Materials Science, Centre for Energy Research, P.O.B. 49, H-1525

Budapest, Hungary

\section{Menyhárd ( $\nabla$ menyhard.miklos@energia.mta.hu )}

Institute for Technical Physics and Materials Science, Centre for Energy Research, P.O.B. 49, H-1525

Budapest, Hungary

\section{E Baradács}

Department of Solid State Physics, Faculty of Sciences and Technology, University of Debrecen, P.O. Box 400, H-4002 Debrecen, Hungary

\section{B Parditka}

Department of Solid State Physics, Faculty of Sciences and Technology, University of Debrecen, P.O. Box 400, H-4002 Debrecen, Hungary

\section{Cserháti}

Department of Solid State Physics, Faculty of Sciences and Technology, University of Debrecen, P.O. Box 400, H-4002 Debrecen, Hungary

\section{G. A Langer}

Department of Solid State Physics, Faculty of Sciences and Technology, University of Debrecen, P.O. Box 400, H-4002 Debrecen, Hungary

\section{Z Erdélyi}

Department of Solid State Physics, Faculty of Sciences and Technology, University of Debrecen, P.O. Box 400, H-4002 Debrecen, Hungary

\section{Research Article}

Keywords: electron beam induced defects, 0 diffusion in Al203, buried layer patterning, defect enhanced Si diffusion

Posted Date: February 5th, 2021

DOI: https://doi.org/10.21203/rs.3.rs-191539/v1 
License: (c) (i) This work is licensed under a Creative Commons Attribution 4.0 International License. Read Full License

Version of Record: A version of this preprint was published at Scientific Reports on April 29th, 2021. See the published version at https://doi.org/10.1038/s41598-021-88808-1. 


\title{
Interface Induced Diffusion; Area Selective Interface Patterning
}

\author{
S. Gurbán ${ }^{1}$, A Sulyok ${ }^{1}$, M. Menyhárd ${ }^{1}$, E. Baradács ${ }^{2,3}$, B. Parditka ${ }^{2}$, C. Cserháti², G. A. \\ Langer $^{2}$, Z. Erdélyi ${ }^{2}$
}

${ }^{1}$ Institute for Technical Physics and Materials Science, Centre for Energy Research, P.O.B. 49, H-1525 Budapest, Hungary

${ }^{2}$ Department of Solid State Physics, Faculty of Sciences and Technology, University of Debrecen, P.O. Box 400, H-4002 Debrecen, Hungary

${ }^{3}$ Department of Environmental Physics, University of Debrecen, H-4026 Debrecen, Poroszlay u. 6, Hungary

\section{*Corresponding author:}

\section{Dr. Miklos Menyhard}

Thin Film Department

Institute for Technical Physics and Materials Science

Centre for Energy Research

P.O.B. 49, H-1525 Budapest

Hungary

Phone: +36306001063

Email: menyhard.miklos@energia.mta.hu

\begin{abstract}
Interface induced diffusion had been identified in thin film system damaged by electron bombardment. This new phenomenon was observed in $\mathrm{Al}_{2} \mathrm{O}_{3}$ (some nm thick) / Si substrate system, which was subjected to low energy $(5 \mathrm{keV})$ electron bombardment producing defects in the $\mathrm{Al}_{2} \mathrm{O}_{3}$ layer. The defects produced partially relaxed. The rate of relaxation is, however, different in the surrounding of the interface and in the "bulk" parts of the $\mathrm{Al}_{2} \mathrm{O}_{3}$ layer. This difference generates an oxygen concentration gradient and consequently oxygen diffusion, resulting in an altered layer which grows from the $\mathrm{Al}_{2} \mathrm{O}_{3} / \mathrm{Si}$ substrate interface. The relative rate of the diffusion and relaxation is strongly temperature dependent, resulting in various altered layer compositions, $\mathrm{SiO}_{2}$ (at room temperature), $\mathrm{Al}_{2} \mathrm{O}_{3}+\mathrm{AlO}_{\mathrm{x}}+\mathrm{Si}$ (at $500^{\circ} \mathrm{C}$ ), $\mathrm{Si}\left(\right.$ at $700^{\circ}$ $\mathrm{C}$ ), as the temperature during irradiation varies. Utilizing this finding it is possible to make area selective interface patterning.
\end{abstract}

Keywords: electron beam induced defects, $\mathrm{O}$ diffusion in $\mathrm{Al}_{2} \mathrm{O}_{3}$, buried layer patterning, defect enhanced Si diffusion 


\section{INTRODUCTION}

Diffusion decreases the difference in chemical potential, which, in the simplest cases, manifests as concentration gradient. Concentration gradient is naturally present if two (or more) materials of various concentrations become connected, or if foreign atoms are placed into a matrix (ion implantation amongst others).

It has long been established that electron irradiation might cause defects in solids initiating various alterations. Hong et al applied electron beam irradiation to affect the grain growth of Ag layer to enhance the optoelectronic properties of the Ag reflector in light emitting diode ${ }^{1}$, Liu et al observed electron radiation-induced material diffusion in nanostructured amorphous $\mathrm{CoFeB}$ thin film ${ }^{2}$, Messina et al calculated the enhancement of diffusion due to the radiation induced point defects ${ }^{3}$, etc. In these cases, the diffusion was studied within the irradiated region. A different situation occurs if irradiation affects only a limited region of the material and the presence of the altered, damaged region initiates normal "diffusion to or form the remaining, undisturbed part of the specimen. For example, Chih-Hao et al. showed ${ }^{4}$ that the interface exhibiting damage induced point defect gradient and/or strain might initiate even uphill diffusion.

In our previous paper ${ }^{5}$ we have studied effect of electron bombardment on the $\mathrm{Al}_{2} \mathrm{O}_{3}$ / Si substrate system since this structure is frequently applied in photovoltaic applications ${ }^{6,7}$. It was observed that due to room temperature electron bombardment, a $\mathrm{SiO}_{2}$ layer had grown on the $\mathrm{Al}_{2} \mathrm{O}_{3} / \mathrm{Si}$ interface. The growth of the $\mathrm{SiO}_{2}$ layer could be described by the CabreraMott model ${ }^{8}$.

The next step in this research, which is the topic of this paper, was the study of the effect of the sample temperature on the electron bombardment irradiation induced alteration of the $\mathrm{Al}_{2} \mathrm{O}_{3}$ / Si substrate system. A great variety of alterations occur when varying the sample temperature during irradiation, from serious degradation of the sample $\left(500^{\circ} \mathrm{C}\right)$ to slight metallic $\mathrm{Si}$ diffusion to the nearly perfect $\mathrm{Al}_{2} \mathrm{O}_{3}$ layer $\left(700^{\circ} \mathrm{C}\right)$. To explain the experimental findings, we will apply the interface induced diffusion process. In our case, however, not the defect and/or strain accumulation at the interface promotes the diffusion, rather the difference of the relaxation rates of the electron bombardment produced defects (broken chemical bonds). This newly discovered process offers novel application as well. It allows a unique possibility to write at the $\mathrm{Al}_{2} \mathrm{O}_{3}$ / Si interface with different "colors" resulting in a double pattering as the transformation at the interface is markedly different at various temperatures. Similar processes and possible applications are even more active in nano materials having many interfaces.

\section{RESULTS}

In this study similar samples have been used as in the previous study ${ }^{5}$, where the initial state of the samples had been carefully characterized and published. Its summary is as follows: the in-depth composition had been determined by AES depth profiling (see depth profiles in Figs. 4a and 5a in ref 5) and the initial interface had been found to be a sharp with thickness of less than $0.5 \mathrm{~nm}$. The interface consists a slight $\mathrm{Si}$ oxide contamination in the range of 0.1-0.3 monolayer. It should be added that in all experiments to be reported the non- 
irradiated regions of the sample was also depth profiled and no deviations from the above were found.

\section{Irradiation at room temperature}

The results of irradiation of $5 \mathrm{~nm} \mathrm{Al}_{2} \mathrm{O}_{3}$ / Si substrate sample have been reported ${ }^{5}$. Since the effects of the irradiation at elevated temperature are much stronger than that at room temperature, besides the previously applied $5 \mathrm{~nm} \mathrm{Al}_{2} \mathrm{O}_{3}$ / Si substrate sample, we also used thicker, $20 \mathrm{~nm} \mathrm{Al}_{2} \mathrm{O}_{3} / \mathrm{Si}$ substrate sample. To check if the layer thickness affects the phenomena first we irradiated the $20 \mathrm{~nm}$ thick sample at room temperature. Figure 1a shows the in-depth concentration distributions determined on sample of $5 \mathrm{~nm} \mathrm{Al}_{2} \mathrm{O}_{3}$ / Si substrate after electron irradiation at room temperature of $5 \mathrm{keV}, \mathrm{I}=500 \mathrm{nA}, 21 \mathrm{~h}$, while Fig. $1 \mathrm{~b}$ shows the in-depth concentration distributions obtained after similar electron irradiation on sample $20 \mathrm{~nm} \mathrm{Al} \mathrm{O}_{3} / \mathrm{Si}$ substrate. The origin of the depth scale is set to the adlayer/substrate interface; the positive and negative direction is toward the adlayer and substrate, respectively.

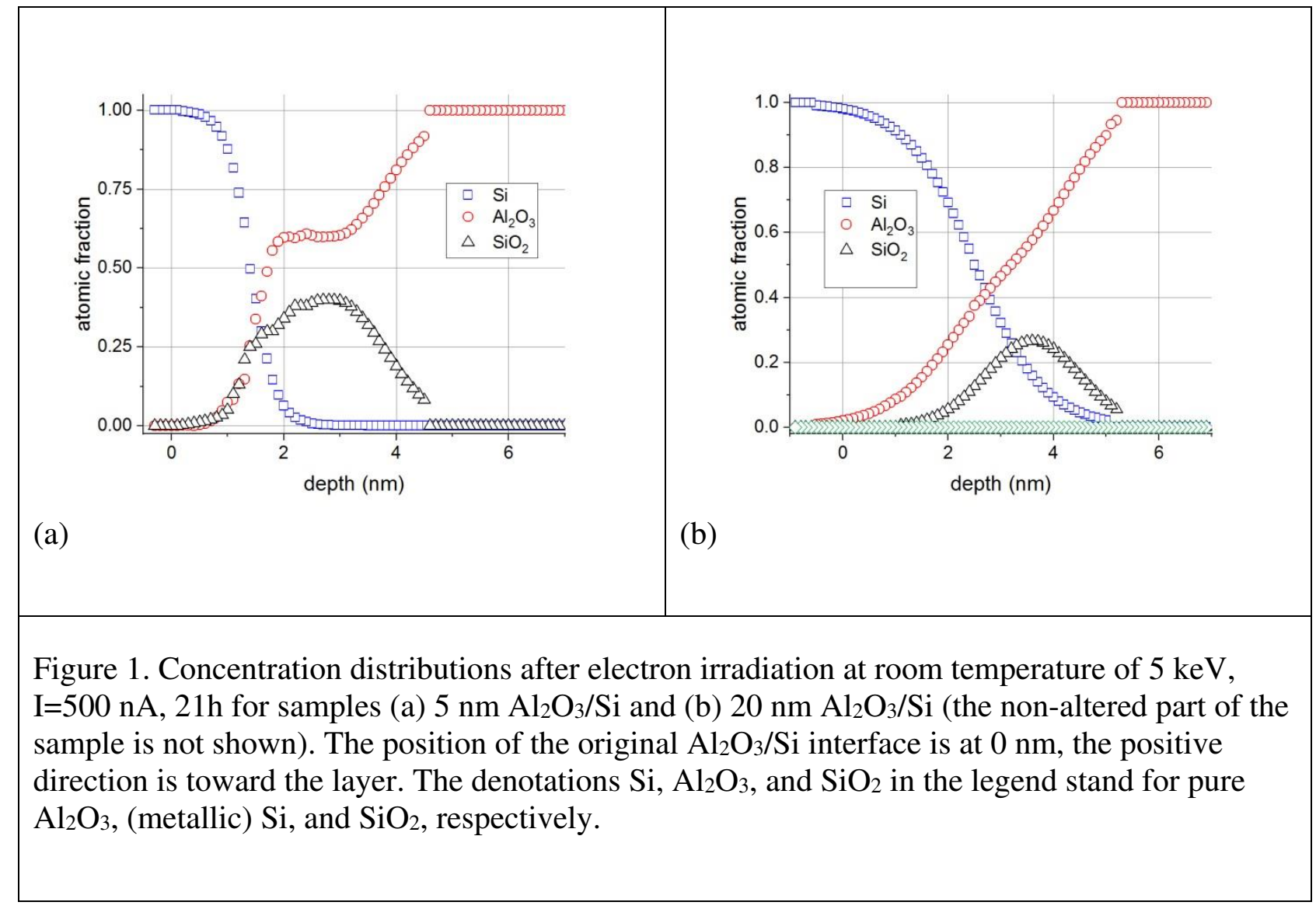

Figure $1 \mathrm{~b}$ shows that in the case of the $20 \mathrm{~nm} \mathrm{Al}_{2} \mathrm{O}_{3} / \mathrm{Si}$ substrate sample the majority of the $\mathrm{Al}_{2} \mathrm{O}_{3}$ layer remained unchanged while close to the $\mathrm{Si} / \mathrm{Al}_{2} \mathrm{O}_{3}$ interface a $\mathrm{SiO}_{2}$ layer forms due to the electron irradiation. The formation of the $\mathrm{SiO}_{2}$ layer in the case of the other sample, $5 \mathrm{~nm} \mathrm{Al}_{2} \mathrm{O}_{3}$ / Si substrate (Fig. 1a), is qualitatively similar. Obviously here the majority of the $\mathrm{Al}_{2} \mathrm{O}_{3}$ layer is affected. 


\section{Irradiation at elevated temperature.}

It was always checked if the heating alone affects the layer system; the irradiated region was negligibly small- it is in the range of $80-150 \mu \mathrm{m}$ in diameter versus $1 \mathrm{~cm}^{2}$ the whole areacompared to the whole area of the sample and thus the neighbouring heated but not irradiated region could be and was always simultaneously depth profiled. It turns out that for any time and temperature combination of the heating (in the range of $20-750^{\circ} \mathrm{C}$ ), the non-irradiated regions of the sample (that is the major part) did not show any changes; the in-depth distributions recorded agreed well with that obtained on the pristine sample. Irradiations at $500{ }^{\circ} \mathrm{C}$

If the irradiation took place at $500^{\circ} \mathrm{C}$ for sufficiently long time, the $\mathrm{Al}_{2} \mathrm{O}_{3} / \mathrm{Si}$ substrate system exhibited serious changes. To demonstrate this, the as-recorded differentiated Auger spectrum is shown in Fig. 2 which was obtained in a depth of $3.2 \mathrm{~nm}$ (measured from the free surface) on sample of $5 \mathrm{~nm} \mathrm{Al} \mathrm{O}_{3} / \mathrm{Si}$ substrate after $16 \mathrm{~h}$ irradiation with $500 \mathrm{nA}$; sample temperature during irradiation was $500^{\circ} \mathrm{C}$.

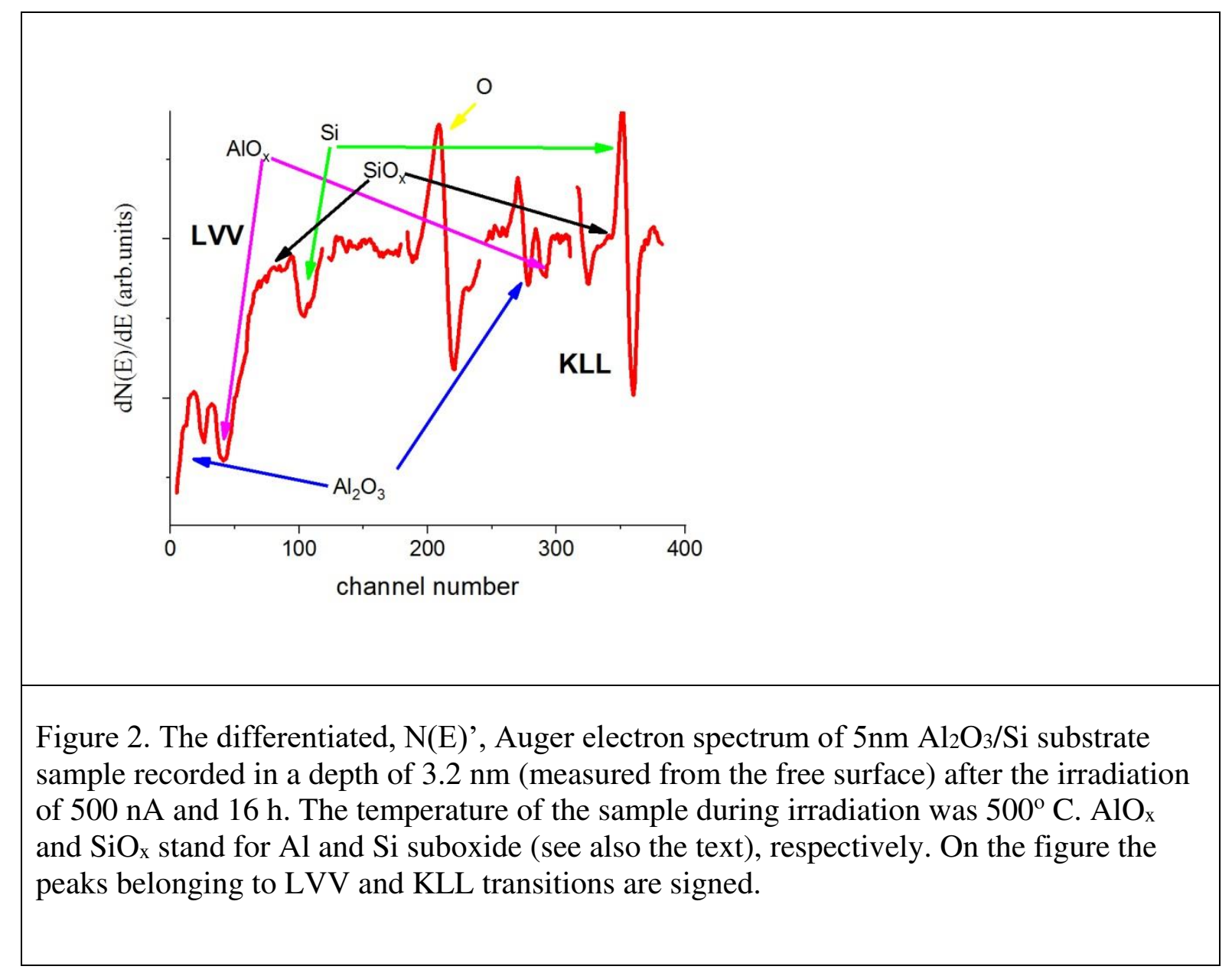

According to Fig. 2 the originally pure $\mathrm{Al}_{2} \mathrm{O}_{3}$ layer drastically changed due to the irradiation. The most important changes are: a./ metallic $\mathrm{Si}$ (not in oxide sate) is in the originally pure $\mathrm{Al}_{2} \mathrm{O}_{3}$ matrix, b./ besides the $\mathrm{Al}$ Auger peaks (LVV and KLL) in oxide bond, new features appear, which can be identified as sub-stoichiometric aluminum oxide (suboxide) - will be 
denoted as $\mathrm{AlO}_{\mathrm{x}}-$, where $0<\mathrm{x}<2$, c./ there is no silicon oxide and/or suboxide denoted as $\mathrm{SiO}_{\mathrm{x}}$. The shapes and positions of KLL and LVV transitions of both $\mathrm{Al}$ and Si strongly changes with oxidation. It should also be emphasized that for suboxides the above energies are different; this change is larger for the LVV (containing valence transitions) Auger peaks than that of the KLL Auger peaks. Thus, the AlLvv line will be used to follow the chemical change along the depth. Some examples (taken from depth profile of samples with 20 and 5 nm thick $\mathrm{Al}_{2} \mathrm{O}_{3}$, resp.) are shown in Fig. 3.

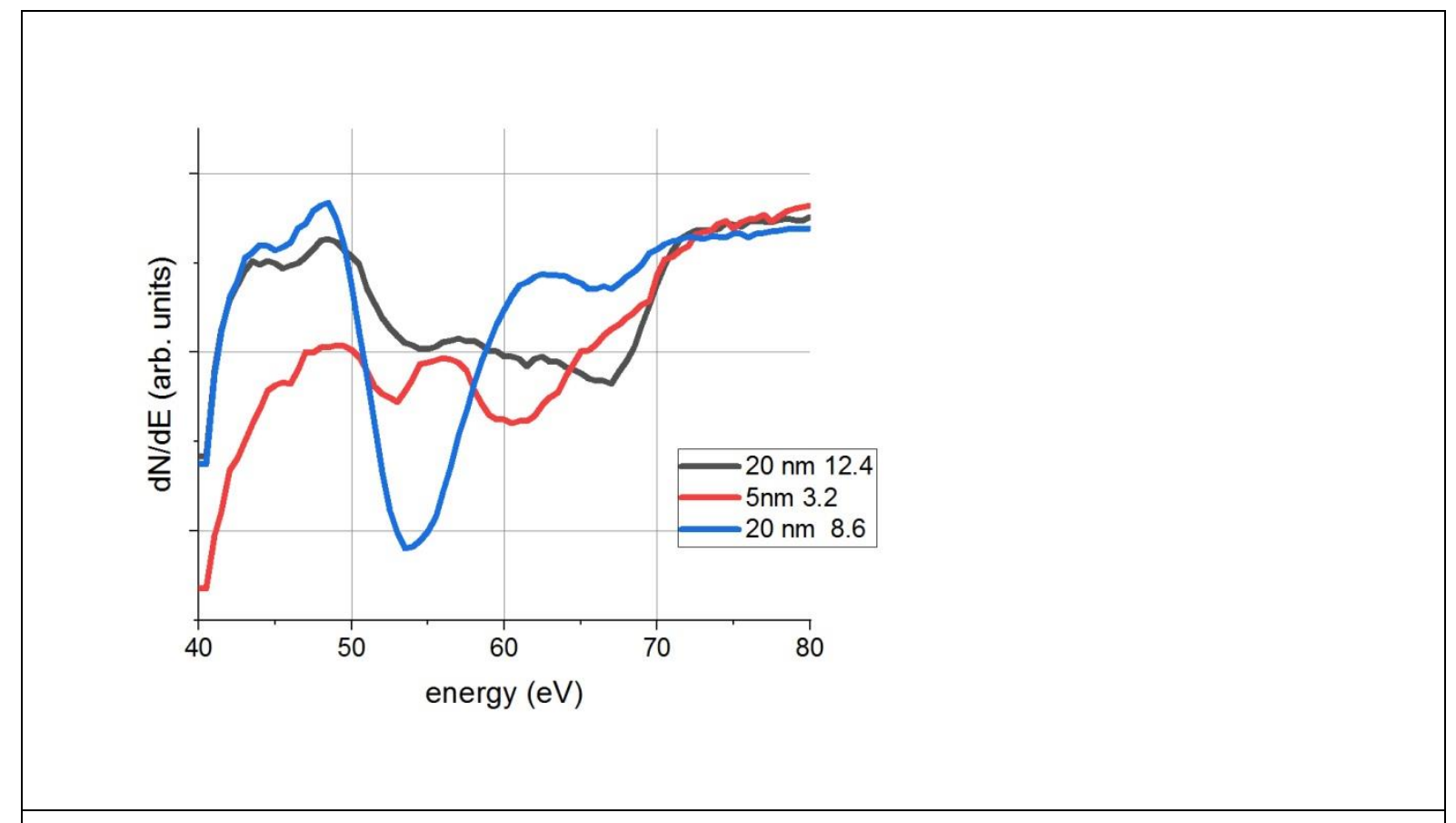

Figure 3. AllLv lines in various depths (measured from the free surface) and samples (with $20 \mathrm{~nm}$ and $5 \mathrm{~nm}$ thick $\mathrm{Al}_{2} \mathrm{O}_{3}$ layers, resp.); the last number in the legend gives the depth (in $\mathrm{nm}$, measured from the free surface) of the region providing the Auger line.

It is clear that the chemical state of the $\mathrm{Al}$ varies with depth. In the following figures only two $\mathrm{Al}$ related concentrations will appear; one for the stoichiometric $\mathrm{Al}_{2} \mathrm{O}_{3}$ state and one for the reminder aluminium oxides, that is, for all different kinds of $\mathrm{AlO}_{\mathrm{x}}$ suboxides (containing various oxygen deficits).

The amount of damage created by the electron bombardment also depends on the dose of the irradiation. This is demonstrated in Fig. 4. It shows the concentration distributions vs. depth for irradiation by Q and 2Q electrons denoted by $s$ and $l$, respectively in the case of a $20 \mathrm{~nm} \mathrm{Al}{ }_{2} \mathrm{O}_{3} / \mathrm{Si}$ substrate sample. 


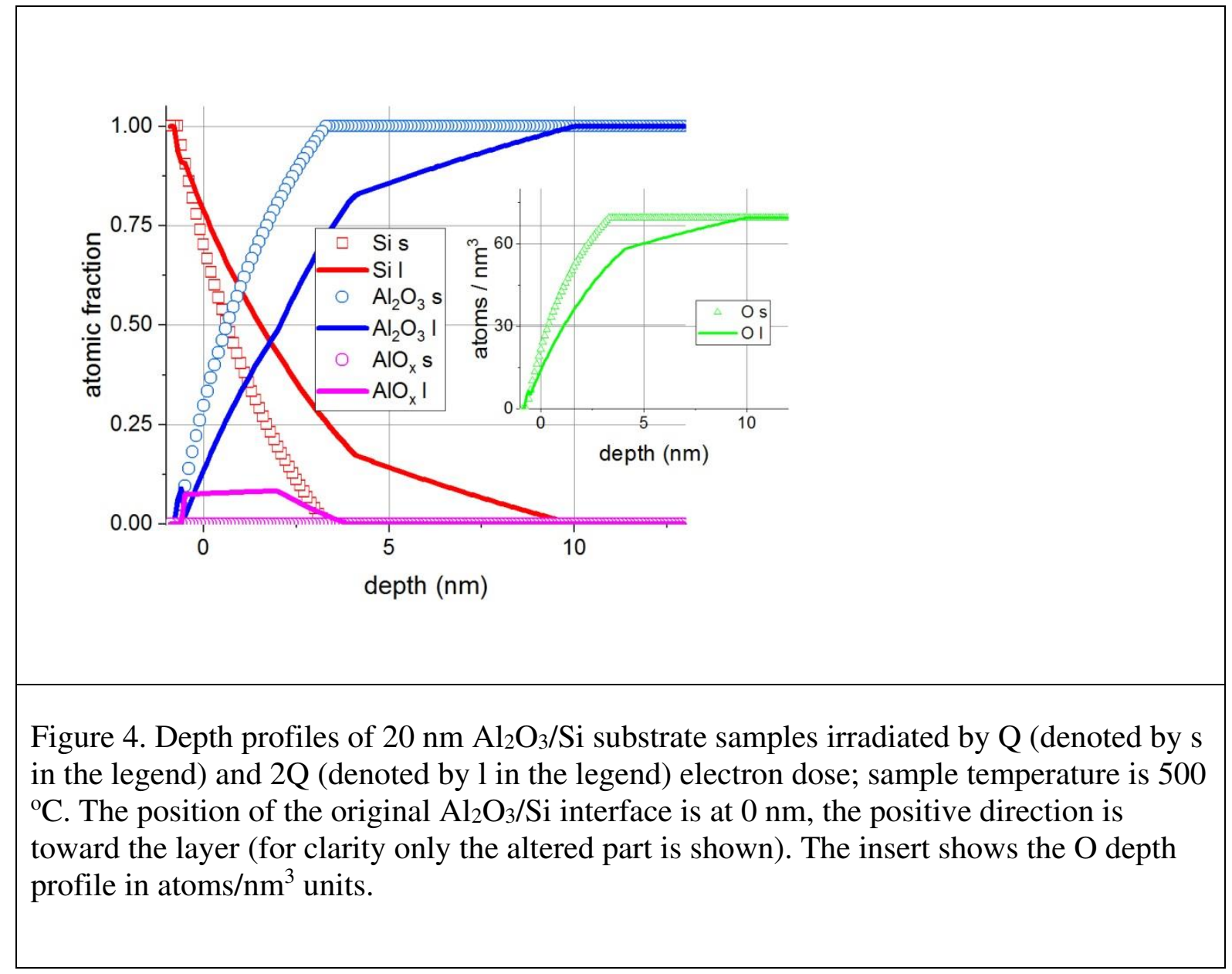

Figure 4 demonstrates that irradiation with higher dose causes higher alterations. The effect of irradiation also depends on the thickness of the $\mathrm{Al}_{2} \mathrm{O}_{3}$ layer. This is demonstrated by Fig. 5; it shows the concentration depth profiles measured on samples with $5 \mathrm{~nm}$ and $20 \mathrm{~nm} \mathrm{Al}_{2} \mathrm{O}_{3}$ layers, after the same, $5 \mathrm{keV}, \mathrm{I}=500 \mathrm{nA}, 20 \mathrm{~h}$, electron irradiation. 


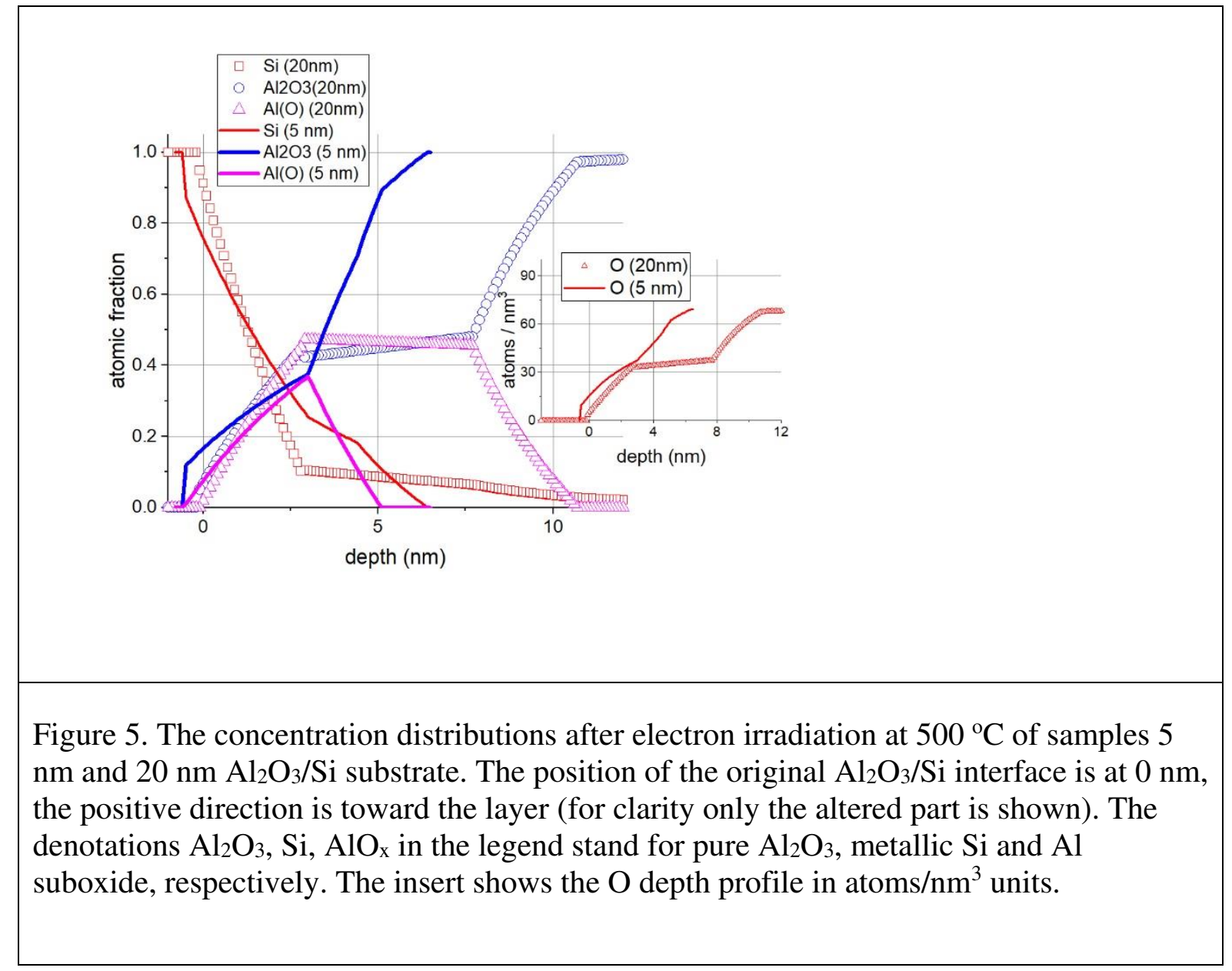

Qualitatively the two types of samples show similar results, which can be summarized as follows:

a./ a layer of the mixture of $\mathrm{AlO}_{\mathrm{x}}$ and metallic $\mathrm{Si}$ grows from the $\mathrm{Al}_{2} \mathrm{O}_{3} / \mathrm{Si}$ interface toward the free surface.

b./ there is $\mathrm{SiO}_{2}$ neither in the layer nor at the $\mathrm{Al}_{2} \mathrm{O}_{3} / \mathrm{Si}$ interface

c./ the oxygen (in oxide bond) decreases toward the interface

\section{Irradiations at $700^{\circ} \mathrm{C}$}

If the irradiation occurs at $700{ }^{\circ} \mathrm{C}$, again a new type of alteration occurs as it is shown in Fig. 6. 


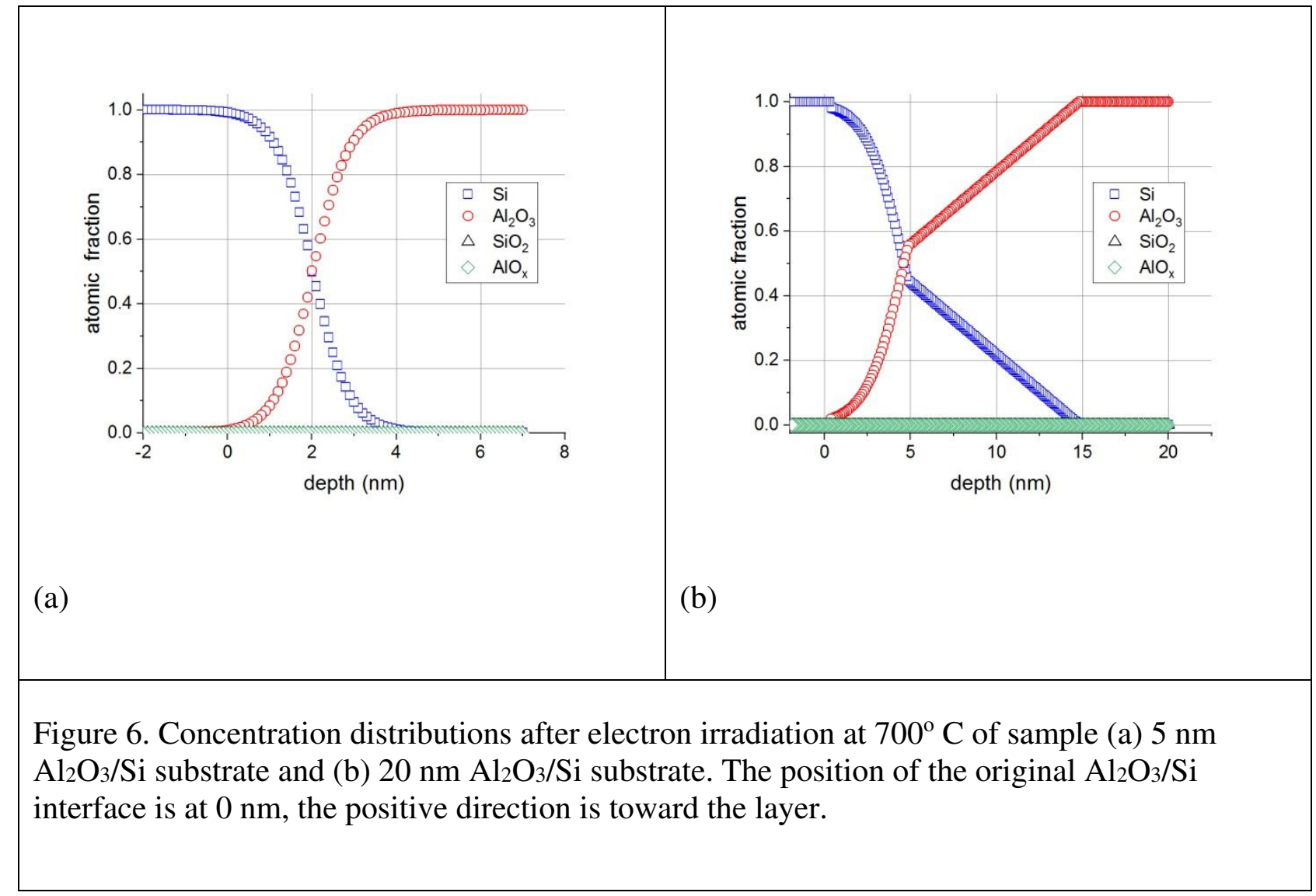

In contrast to the alteration which is produced by the irradiation if the sample temperature is $500{ }^{\circ} \mathrm{C}$, in this case the $\mathrm{Al}_{2} \mathrm{O}_{3}$ layer seems to be untouched, consequently there is no oxygen diffusion. On the other hand, metallic silicon diffuses into the $\mathrm{Al}_{2} \mathrm{O}_{3}$ layer. Note that the sensitivity of the AES is around 5-7 at\%.

\section{DISCUSSION}

Let us first summarize the experimental findings:

At the irradiated area:

a./ in all experiments there is always a region connected to the free surface which is free from any alteration

b./ all alterations scale with the dose of electron irradiation

c./ in the $20-700{ }^{\circ} \mathrm{C}$ temperature range the following alterations were observed:

- at room temperature $\mathrm{SiO}_{2}$ is produced at the interface ${ }^{5}$ 
- at $500^{\circ} \mathrm{C} \mathrm{AlO}_{x}$ suboxide $(0<\mathrm{x}<2)$ and metallic Si mixture appears in the $\mathrm{Al}_{2} \mathrm{O}_{3}$ layer growing from the $\mathrm{Al}_{2} \mathrm{O}_{3} / \mathrm{Si}$ interface, accordingly, the bound oxygen concentration decreases toward the $\mathrm{Al}_{2} \mathrm{O}_{3} / \mathrm{Si}$ interface

- at $700^{\circ} \mathrm{C}$ the $\mathrm{Al}_{2} \mathrm{O}_{3}$ layer seems to be untouched, but $\mathrm{Si}$ diffuses into the $\mathrm{Al}_{2} \mathrm{O}_{3}$ layer

At the non-irradiated area:

For any heating temperature and time combination the layer system remained unchanged; the measured depth profile was exactly the same as that recorded on the as received sample.

We will show in the following that all these experimental findings, which seem to be very complex, can be explained by a simple model. The model considers only three elementary processes as a./ primary defect production, b./ primary relaxation, c./ diffusion.

Before dealing with the alterations obtained, the basic feature of the $\mathrm{Al}_{2} \mathrm{O}_{3}$ layer is to be considered. These $\mathrm{Al}_{2} \mathrm{O}_{3}$ layer are frequently used as a protection on $\mathrm{Si}$ based photovoltaic devices ${ }^{6,7}$; accordingly, the expectation is that it does not interact with the underlying Si. This behaviour is generally expected and found. Our layers behave similarly, that is, up to $700^{\circ} \mathrm{C}$ even the long heating does not affect the layer system; it is exactly the same as the asreceived one. This means that our layers are good quality; they are meeting the expected features and the heating alone does not result in any changes.

\section{The effect of electron irradiation; primary defect production}

The excitation of defects in the present circumstances has been discussed in our previous paper ${ }^{5}$. Its essence is the following. From the various possible interactions (heating, knock-on ionization, electronic excitation etc.) in the present case the radiolytic processes is active ${ }^{10}$, which is similar to the low-energy electron-stimulated desorption (ESD) ${ }^{11-12}$. Thus, the electron irradiation produces neutral and/or charged $\mathrm{O}$ in the $\mathrm{Al}_{2} \mathrm{O}_{3}$ matrix together with various charged and neutral crystal defects.

The excitation is temperature independent. The excitations are made by the primary electron beam current and the backscattered secondary electrons; the intensity of none of them vary along the $20 \mathrm{~nm}$ or $5 \mathrm{~nm}$ thick $\mathrm{Al}_{2} \mathrm{O}_{3}$ layer. Thus, in the investigated system, the excitation is temperature and depth independent; the primary excited defects and excited $\mathrm{O}$ species are homogeneously distributed in the $\mathrm{Al}_{2} \mathrm{O}_{3}$ layer.

\section{Primary relaxation process}

The production of defects in $\Delta V$ volume of the "bulk" part of the $\mathrm{Al}_{2} \mathrm{O}_{3}$ matrix during $\Delta t$ time is $I_{e} \Delta t A d \sigma_{e}$, where $I_{e}$ is the bombarding electron current, $A$ is the cross section of the electron 
beam, $d$ is the thickness of the layer, while $\sigma_{e}$ is the ionization cross section. We might suppose that the relaxation of defects depends on the number of defects as

$$
\frac{d\left(\rho_{A l} \Delta V\right)}{d t}=s_{d}-\Delta V \rho_{A l} \exp \left(-\frac{Q_{A l}}{k T}\right)
$$

where $\rho_{A l}$ is the defect concentration (volume density) in the $\mathrm{Al}_{2} \mathrm{O}_{3}$ matrix and $Q_{A l}$ is the activation energy for aluminum-oxide formation and $s_{d}$ is the rate of defect production by irradiation. The solution of this equation is

$$
\rho_{A l} \Delta V=\frac{s_{d}}{\lambda_{A l}}\left[1-\exp \left(-\lambda_{A l} t\right)\right]
$$

with $\lambda_{A l}=\exp \left(-\frac{Q_{A l}}{k T}\right)$. Thus, the defect concentration increases until the rate of defect relaxation becomes equal to the rate of defect production and then a dynamic equilibrium is reached $(t \rightarrow \infty$ in eq. (1b))

$\rho_{A l}^{\text {stat }}=\frac{s_{d}}{\lambda_{A l}} \quad(1 \mathrm{c})$

Obviously, the stationary concentration of defects is temperature dependent.

In the surrounding of the adlayer/substrate interface the above process is disturbed by the appearance of a new agent, the $\mathrm{Si}$; $\mathrm{Si}$ can also bind the excited oxygen. Since a new recombination center appears, we should modify eq. (1a) as

$$
\frac{d(\rho \Delta V)}{d t}=s_{d}-\Delta V \rho\left[c_{A l} \exp \left(-\frac{Q_{A l}}{k T}\right)+c_{S i} \exp \left(-\frac{Q_{S i}}{k T}\right)\right]
$$

where $Q_{S i}$ is the activation energy for silicon oxide formation, furthermore $c_{A l}$ and $c_{S i}$ are the fraction of $\mathrm{Al}_{2} \mathrm{O}_{3}$ and $\mathrm{Si}$ in $\Delta V$ volume. This activation energy is higher (see later) than that of $Q_{A l}$, accordingly, the rate of the defect relaxation decreases and thus the stationary defect (excited oxygen) concentration is higher than that in the "bulk" part of the layer. The solution of

eq. $(2 a)$ is

$\rho \Delta V=\frac{s_{d}}{c_{A l} \lambda_{A l}+c_{S i} \lambda_{S i}}\left\{1-\exp \left[-\left(c_{A l} \lambda_{A l}+c_{S i} \lambda_{S i}\right) t\right]\right\}$

where $\lambda_{S i}=\exp \left(-\frac{Q_{S i}}{k T}\right)$, with stationary defect concentration of 


$$
\rho^{s t a t}=\frac{s_{d}}{c_{A l} \lambda_{A l}+c_{S i} \lambda_{S i}}
$$

Note that $\rho_{A l}^{\text {stat }}<\rho^{\text {stat }}$ if $Q_{A l}<Q_{S i}$.

\section{Diffusion}

Based on the above because of the presence of interface a concentration gradient of excited oxygen is built up. The diffusivity $(D)$ of oxygen in $\mathrm{Al}_{2} \mathrm{O}_{3}$ is in the range of $4.6 \times 10^{-}$ ${ }^{34}-1.3 \times 10^{-32} \mathrm{~m}^{2} / \mathrm{s}$, and $2.9 \times 10^{-22}-1.1 \times 10^{-21} \mathrm{~m}^{2} / \mathrm{s}$, at room temperature and at $500^{\circ} \mathrm{C}$, respectively ${ }^{13,14}$.

Now we will explain the experimental findings based on the above.

\section{General observations (experimental findings $a$ and $b$ )}

a. / It has been found that there was always an unhurt region connected to the free surface. Thus, in this region the concentration of defects (if they exist at all) is less than some percentage which is the sensitivity level of our analysis. To explain this finding we suppose that $Q_{A l}$ in the surface close region is different, lower, than that in the "bulk" value since in this region atomic reconstruction is possible.

b./ The number of defects is proportional to the exciting current (eqs. (1) and (2)) and, as all processes depend on the number of defects, dependence on the dose is evident.

\section{Alteration as a function of temperature}

\section{- room temperature}

At room temperature irradiation $\mathrm{SiO}_{2}$ formation occurs though at room temperature the diffusion length $(\sqrt{D t})$ of excited oxygen in one day $(t=24 h)$ is in the range of $6.3 \times 10^{-6}$ $3.3 \times 10^{-5} \mathrm{~nm}$, is is negligible. Accordingly, at room temperature there is excited oxygen at the interface, which cannot depart because of the low diffusion rate, and thus it might interact with the Si and oxide formation occurs. This oxide can have a limited growth according to the Cabrera and Mott process ${ }^{8}$ detailed in our previous paper ${ }^{5}$. The amount of oxide produced does not depend on the actual layer thickness since only the primary excitation is to be considered, which is homogeneous along the depth.

$-500^{\circ} \mathrm{C}$

In contrary to the modest changes at room temperature, at $500{ }^{\circ} \mathrm{C}$ net oxygen loss and consequently a mixture of $\mathrm{Al}_{2} \mathrm{O}_{3}, \mathrm{Al}$ suboxide $\left(\mathrm{AlO}_{\mathrm{x}}\right)$ layer formation, and $\mathrm{Si}$ diffusion 
toward the free surface occur. Here we should consider that at $500{ }^{\circ} \mathrm{C}$ the excited oxygen is already mobile; its diffusion length is in the range of 5-10 $\mathrm{nm}$ allowing oxygen transport.

In the surrounding of the interface the concentration of the excited oxygen is higher than that in the "bulk" $\mathrm{Al}_{2} \mathrm{O}_{3}$ because of the higher activation energy of the silicon oxide formation, thus an oxygen gradient toward the free surface is developing. At this temperature the "physisorbed" oxygen easily desorbs to the vacuum from the surface of the $\mathrm{Al}_{2} \mathrm{O}_{3}$, thus an oxygen current develops due to the electron irradiation and a net oxygen loss appears. As the oxygen diffuses away a region with sub-stoichiometric $\mathrm{AlO}_{\mathrm{x}}$ develops with varying oxygen content (see Fig. 2-3.) This region, attached to the Si substrate, contains various defects and induces enhanced metallic Si diffusion. This observation corroborates the assumption that the activation energy of the $\mathrm{Si}-\mathrm{O}$ bond formation is higher than that of $\mathrm{Al}-\mathrm{O}$; in this defected region in the presence of $\mathrm{AlO}_{\mathrm{x}}$ the metallic $\mathrm{Si}$ has no chance for making $\mathrm{Si}-\mathrm{O}$ bond. The defected region growths, Fig. 4, to the originally pure $\mathrm{Al}_{2} \mathrm{O}_{3}$ matrix and thus the interface also migrates. Thus, the region with higher excited oxygen concentration than that of pure $\mathrm{Al}_{2} \mathrm{O}_{3}$ also migrates and drives the diffusion. This oxygen "pump" is so effective that even the oxygen, which was initially present on the $\mathrm{Al}_{2} \mathrm{O}_{3}$ / Si substrate interface is also carried away.

$-700^{\circ} \mathrm{C}$

If the electron irradiation occurs at $700{ }^{\circ} \mathrm{C}$ the $\mathrm{Al}_{2} \mathrm{O}_{3}$ seems to be unhurt, that is the number of defects is lower than 5\% (the sensitivity of the AES is around 5\%) and Si diffusion occurs. Evidently the primary defect formation active, thus excited oxygen is produced by the irradiation. Its stationary level is, however, strongly temperature dependent (see eqs. (1c) and (2c)). Taking, for example, eq. (1c), we can estimate the factor by which the stationary level of defect density is decreased due to the increase of the temperature

$\frac{\rho_{A l}^{s t a t}\left(T_{h}\right)}{\rho_{A l}^{s t a t}\left(T_{l}\right)}=\exp \left[\frac{Q_{A l}}{R}\left(\frac{1}{T_{l}}-\frac{1}{T_{h}}\right)\right]$

Considering that the activation energy is in the order of eV and that $T_{h}=700^{\circ} \mathrm{C}$ and $T_{l}=500^{\circ} \mathrm{C}$, we obtain that the decrease is at least one to two orders of magnitude. Similar factor is obtained for the interface region, that is for $\frac{\rho^{\text {stat }}\left(T_{h}\right)}{\rho^{\text {stat }}\left(T_{l}\right)}$. Accordingly, the concentration gradient of excited oxygen is also decreased by at least one to two orders of magnitude, and thus the driving force for diffusion practically vanishes. This is in agreement with the experimental findings that no defects (higher than 5\%) were observed. It should be concluded that the relaxation process is faster than that of diffusion, thus practically all oxygen binds back before the diffusion can transport it away.

Still thermally activated Si diffusion occurs. Here we note that Si movement was also observed at room temperature since $\mathrm{SiO}_{2}$ formation occurred, that movement was, however, not thermally activated diffusion but by the Cabrera-Mott process; see also ref. 5. To explain 
the observed diffusion, we recall that defect production is temperature independent thus defect formation occurs during irradiation at $700^{\circ} \mathrm{C}$. According to eq. (1) to reach the stationary state the presence of some defects is necessary, thus the $\mathrm{Al}_{2} \mathrm{O}_{3}$ layer should contain defects. We have not found diffusion data for the $\mathrm{Si} / \mathrm{Al}_{2} \mathrm{O}_{3}$ system but it is safe to suppose that at this higher temperature defect enhanced Si diffusion occurs.

By fitting the Si distribution profiles in Fig. 6, assuming that they were produced by diffusion, we may deduce the interdiffusion coefficient for the defected $\mathrm{Al}_{2} \mathrm{O}_{3} / \mathrm{Si}$.

Time development of the composition profile in Fig. 6(a) can be obtained from the solution of Fick's second equation when the initial condition is a step function ${ }^{15,16}$

$$
c(x, t)=\frac{1}{2} \operatorname{erfc}\left(\frac{x-x_{0}}{2 \sqrt{D t}}\right),
$$

where $c$ is the atomic fraction of the diffusion specie and $x_{0}$ is the position of the center of the profile (Matano plane). Fitting this to the composition profile of Si in Fig. 6(a), a value of $2.7 \times 10^{-24} \mathrm{~m}^{2} / \mathrm{s}$ is obtained for diffusion coefficient. (see Fig. 7 (a))

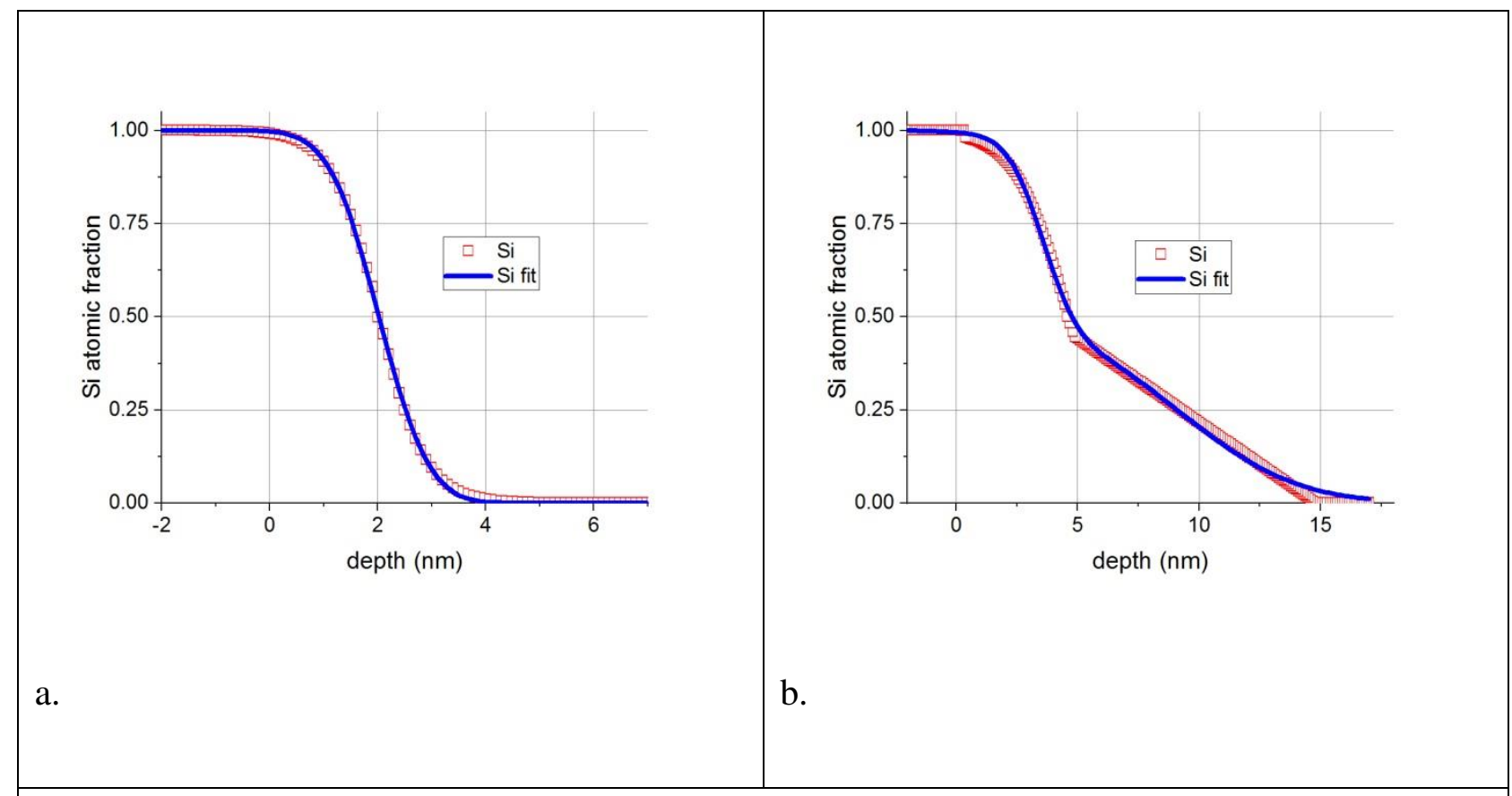

Figure 7. Fit of the composition profiles by erfc function to deduce the diffusion coefficients, for samples irradiated at $700^{\circ} \mathrm{C}$ : (a) $5 \mathrm{~nm} \mathrm{Al}_{2} \mathrm{O}_{3} / \mathrm{Si}$ substrate, (b) $20 \mathrm{~nm} \mathrm{Al}_{2} \mathrm{O}_{3} / \mathrm{Si}$ substrate. Solid lines are the fitted curves.

We can see, however, that the composition profile in Fig. 6(b) cannot be fitted by a single error function. This diffusion process seems to be governed by two activation energies; typical for short-circuit diffusion (e.g. grain boundaries). For this reason, as a simple model, 
instead of using a single erfc function, we fitted the depth profile by a function consisting of two erfc functions containing two diffusion coefficients; one for the bulk diffusion $(D)$ and one valid in the short circuit $\left(D^{\prime}\right)$. Although this is an oversimplified model - important structural parameters to build a robust model are unknown, it gives surprisingly reasonable results. (see Fig. 7 (b)) The bulk diffusion coefficient is of $7.9 \times 10^{-24} \mathrm{~m}^{2} / \mathrm{s}$, whereas the short circuit one is $D^{\prime}=1.2 \times 10^{-22} \mathrm{~m}^{2} / \mathrm{s}$. As can be seen, the values of the bulk diffusion coefficients are practically the same for the two samples. The short-circuit diffusion is explained by the imperfections built in the sample; e.g. pinholes are typical in $\mathrm{Al}_{2} \mathrm{O}_{3}$. In the 5 $\mathrm{nm}$ distance range from the interface, the volume and short-circuit diffusion overlap, while the Si can reach farther than $5 \mathrm{~nm}$ only by short-circuit diffusion.

To conclude the discussion, we note that according to eqs. (1) and (2) the lower the temperature the higher the stationary concentration of excited oxygen is. This means that the highest level is expected at room temperature, hence the gradient of the defects is also the highest. At this temperature, however, the oxygen is immobile, consequently they cannot depart from the interface but can react with the silicon atoms being there, resulting in a $\mathrm{SiO}_{2}$ layer. At $500^{\circ} \mathrm{C}$ the oxygen is already mobile, the saturation density of the excited oxygen is still high enough to be detected and also its gradient large enough to provide sufficient driving force for diffusion. As a consequence, oxygen diffusion starts towards the free surface. No reaction with $\mathrm{Si}$ is possible, even oxygen debt is observed in the interface region. At $700^{\circ} \mathrm{C}$ the density of the exited oxygen is low, cannot be detected, which also means that its gradient is negligible, so although oxygen would be mobile, the driving force for diffusion is missing. As a result, the excited oxygen stays in place and bind back quickly. Si can, however, move already at this temperature in the defected $\mathrm{Al}_{2} \mathrm{O}_{3}$, although the level of the defects is low but definitely higher than without irradiation.

\section{Area selective double interface patterning}

Finally, we will propose an application of the observed phenomenon.

It was shown that due to the electron irradiation a well-defined layer grows at the interface, which is highly stable. The composition of the layer, however, depends on the temperature during irradiation; at room temperature, $500^{\circ} \mathrm{C}$ and $700^{\circ} \mathrm{C}, \mathrm{SiO}_{2}, \mathrm{Al}$ with $\mathrm{AlO}_{\mathrm{x}}$ and $\mathrm{Si}$ form, respectively. This gives us the unique possibility to make various templates of different "colors" on an interface. We may first write a pattern by the piloted e-beam at the interface at room temperature (first pattern in color 1) then at $500^{\circ} \mathrm{C}$ (second pattern in color 2 ), and finally at $700^{\circ} \mathrm{C}$ (third pattern in color 3).

\section{Conclusions}

5 and $20 \mathrm{~nm} \mathrm{Al}_{2} \mathrm{O}_{3} / \mathrm{Si}$ substrate layer systems were irradiated by $5 \mathrm{keV}$ electrons up to a dose of $3 \times 10^{7} \mathrm{e} / \mathrm{nm}^{2}$ at various temperatures in the range of $20-700^{\circ} \mathrm{C}$. The layer system was stable; the non-irradiated regions of the sample were not affected by the heating. On the other hand, the electron irradiation affected the layer system. The irradiation induced various alterations depend on the irradiation dose and temperature but the modified zone was always nucleated at the interface. At room temperature irradiation a thin $(2-3 \mathrm{~nm}) \mathrm{SiO}_{2}$ was produced 
independently from the thickness of the initial $\mathrm{Al}_{2} \mathrm{O}_{3}$ layer. If the irradiation took place at $500^{\circ} \mathrm{C}$ a mixture of $\mathrm{Al}_{2} \mathrm{O}_{3}$ and $\mathrm{AlO}_{\mathrm{x}}(0<\mathrm{x}<2)$ were produced and simultaneously Si diffusion toward the free surface occurred. During this process considerable loss of O occurred. This damaged region was grown from the interface toward the free surface with increasing irradiation dose. If the irradiation took place at $700^{\circ} \mathrm{C}$ the integrity of the $\mathrm{Al}_{2} \mathrm{O}_{3}$ layer was only slightly affected and defect enhanced Si diffusion toward the free surface was observed.

A simple model has been developed considering electron bombardment induced bond breaking, relaxation and diffusion describes all the experimental findings. Its essence is that the relaxation of the defects in the interface region is different from that of the bulk resulting in an excess excited oxygen concentration in the interface region because of the presence of the interface, that is, all processes observed are prompted by the presence of the interface. This excess oxygen concentration drives the $\mathrm{O}$ diffusion toward the free surface. The outcome depends on the relative rate of diffusion transport and relaxation. At around $500^{\circ} \mathrm{C}$ the rate of relaxation is lower than the rate of diffusion resulting in a net oxygen loss and formation of aluminium suboxide. At around $700^{\circ} \mathrm{C}$ the rate of relaxation is higher than the rate of diffusion resulting in low density of the exited oxygen, which also means that its gradient is negligible, so although oxygen would be mobile, the driving force for diffusion is missing. On the other hand, the presence of low concentration defects results in defect enhanced Si diffusion.

It was shown, that the temperature dependent phase transformation at the interface gives us the unique possibility to write at the $\mathrm{Si} / \mathrm{Al}_{2} \mathrm{O}_{3}$ interface with different "colors" resulting in a various pattering.

\section{Samples and Methods}

\section{Sample}

Samples were made by growing an $\mathrm{Al}_{2} \mathrm{O}_{3}$ layer on a $\mathrm{Si}(100)$ substrate using atomic layer deposition (ALD); for the details see ref 5.

\section{Electron irradiation}

All electron irradiation experiments have been carried out in our standard Auger Electron Spectroscope (AES), using a standard electron gun; its parameters are: energy 0.1$10 \mathrm{keV}$, beam current 0.1-500 nA, beam diameter (energy dependent) 10-100 $\mu \mathrm{m}$, scanning area up to $3 \times 3 \mathrm{~mm}^{2}$. Because of the low efficiency of the process long irradiation times (16$28 \mathrm{~h}$ ) were applied. As the long-term geometrical stability of our system is not sufficiently good various irradiation protocols have been applied. Generally, the beam scanned a small area, this method proved to be rather reliable but obviously the total dose per unit area is not maximal. If we wanted to apply the highest possible dose, then the beam was standing in a spot. The beam can jump between two points; the irradiation times at the two points are different. Obviously in this case again the total dose is far less than maximal. On the other hand, this mode provided excellent results concerning the dose dependence of the process. Based on the previous it is clear that the error of the value of the total irradiated dose is high. Typical irradiation current density at standing in one spot (applying $500 \mathrm{nA}$ current with 100 $\mu \mathrm{m}$ diameter) is about $400 \mathrm{e} / \mathrm{s} / \mathrm{nm}^{2}$. This number seems to be high but if we consider that the 
cross section for ionization is in the range of $10^{-16} \mathrm{~cm}^{2}$, while the time for primary relaxation (see later) is in the range of $10^{-12} \mathrm{~s}$, we conclude that the interaction events are independent.

The samples were mounted on a sample holder the temperature of which could be varied in the range of $20-800^{\circ} \mathrm{C}$.

\section{AES analysis}

Two types of Auger analysis were applied. During the irradiation at any temperature the surface concentration was monitored. This measurement provides interesting data in the case of the $5 \mathrm{~nm}$ thick sample since all KLL Auger electrons emitted any depth of the layer and the surface close region of the substrate partly leave the sample and can be analysed. This measurement provides a rough description of the of the time evaluation of the alterations. On the other hand, it cannot provide detailed information on the concentration distributions along the depth. The latter can be obtained by AES depth profiling. All depth profiles were recorded on room temperature samples, where the conditions are frozen in. Thus the recorded depth profiles provide the state of the concentration distributions after a given irradiation.

For AES analysis the same electron gun was used for the excitation with a primary current and energy of $50 \mathrm{nA}$ and $5 \mathrm{keV}$, respectively. The low irradiation time and current do not cause additional alterations in the sample.

The Auger spectra, N(E), were recorded by a pre-retarded cylindrical mirror analyzer (DESA 150, Staib) in counting mode. The recorded spectrum was numerically differentiated for calculating the concentration.

The following Auger signals were measured: $\mathrm{Al}_{\mathrm{KLL}}, \mathrm{Al}_{\mathrm{LVV}}, \mathrm{Si}_{\mathrm{KLL}}, \mathrm{SiLVV}$, all cases in metallic and oxide forms, $\mathrm{C}$ and $\mathrm{O}$. The escape depths of the Auger electrons depend on their energy and the matrix they travel. Si and $\mathrm{Al}$ are neighbouring elements and the energy of their LVV and KLL Auger electrons are close. In oxide form there is a larger change (about $14 \mathrm{eV}$ ) of the energy of the Auger electron; thus it is easy their distinction in analysis but this change from the point of view of inelastic mean free paths (IMFP) is small. Similarly, the IMFPs are rather close in $\mathrm{SiO}_{2}$ and $\mathrm{Al}_{2} \mathrm{O}_{3}$; the difference is 20 and $10 \%$ for the LVV and KLL Auger electrons, respectively. Thus, for all LVV and KLL Auger electrons travelling in any available matrix the IMFPs are around $0.7 \mathrm{~nm}$ and $3.3 \mathrm{~nm}$, respectively ${ }^{17}$. By measuring the intensity of the high energy (KLL) and low energy (LVV) Auger electrons simultaneously, a rich data state is obtained, which improves the accuracy of the determination depth distributions of the concentrations.

\section{AES depth profiling}

The parameters of the ion bombardment used for AES depth profiling were: energy 1 $\mathrm{keV}$, projectile $\mathrm{Ar}^{+}$, angle of incidence $80^{\circ}$ (with respect to the surface normal) and specimen rotation during ion bombardment. The ion beam was scanned in an area of $1.5 \times 1.5 \mathrm{~mm}^{2}$. Using these parameters, the ion bombardment induced roughening and mixing is minimal ${ }^{18}$.

\section{Determination of the concentration distribution from AES spectra}


This was made exactly the same way as in ref 5. Its summary is the following: Instead of the usual relative sensitivity factor based routine ${ }^{9}$ we applied our our trial and error approach to determine the composition distribution of such samples ${ }^{19}$. The essence of this method is that we assume a composition distribution along the depth and calculate the Auger intensities assuming that the transport of electrons can be described by the exponential attenuation law. The composition distributions are varied until the simulated depth profile is close enough to the measured one. If one detects high (high IMFP) and low energy (low IMFP) Auger electrons, as in the present case, the accuracy of the method is rather good.

\section{ACKNOWLEDGEMENTS}

This research was funded by the Higher Education Institutional Excellence Program (NKFIH-1150-6/2019) of the Ministry of Innovation and Technology in Hungary, in the framework of the Energetics thematic program of the University of Debrecen.

\section{REFERENCES}

1. Hong I. Y, Islam A. B. M. H, Kim T. K, Yu-Jung Cha, Kwak J. S, Impact of grain growth of silver reflective electrode by electron bombardment on external quantum efficiency of III-nitride micro-light emitting diode arrays, Appl. Sur. Sci. 512, 145698 (2020).

2. Liu B et al, Electron radiation-induced material diffusion and nanocrystallization in nanostructured amorphous CoFeB thin film, Acta Mat. 161, 221-236 (2018).

3. Messina L, Schuler T, Nastar M, Marinica M, Olsson P, Solute diffusion by selfinterstitial defects and radiation-induced segregation in ferritic $\mathrm{FeX}(\mathrm{X}=\mathrm{Cr}, \mathrm{Cu}, \mathrm{Mn}, \mathrm{Ni}$, P, Si) dilute alloys, Acta Mat. 191, 166-185 (2020).

4. Chih-Hao Wang H, Chih-Chiang Wang, Chih-Sheng Chang, Wang T, Griffin P. B, Diaz C. H, Interface Induced Uphill Diffusion of Boron: An Ef,fective Approach for Ultrashallow Junction, IEEE Electron Device Letters, 22, 65-67 (2001).

5. Gurbán $\mathrm{S}$ et al, Electron irradiation induced $\mathrm{SiO}_{2}$ formation at metal oxide / Si interface at room temperature; electron beam writing on interfaces, Sci. Rep. 8, 2124 (2018).

6. Choi $\mathrm{S}$ et al, Structural evolution of tunneling oxide passivating contact upon thermal annealing, Sci. Rep. 712853 (2017).

7. Agostinelli G, Delabie A, Vitanov P, Alexieva Z, Dekkers H.F.W, De Wolf S, Beaucarne G, Very low surface recombination velocities on p-type silicon wafers passivated with a dielectric with fixed negative charge. Sol. Energy Mater. Sol. Cells 90, 3438-3443 (2006).

8. Cabrera N, Mott N. F. Theory of the oxidation of metals. Rep. Prog. Phys. 12, 163-184 (1949).

9. Childs K.D, Carlson B.A, LaVanier L.A, Moulder J.F, Paul D.F, Stickle W.F, Watson D.G, Handbook of Auger Electron Spectroscopy, 3rd ed.; Physical Electronics, Inc.: Eden Prairie, MN, 1995.

10. Hobbs L.W, Pascucci M.R, Radiolysis and defect structure in electron-irradiated $\alpha$ quartz. J. Physique C6, 237-242 (1980).

11. Menzel D, Gomer R, Desorption from metal surfaces by low-energy electrons. J. Chem. Phys. 41, 3311-3328 (1964).

12. Knotek M.L, Feibelman P.J, Ion desorption by Core-Hole Auger Decay. Phys. Rev. Lett. 40, 964-967 (1978). 
13. Nakamura R, Toda T, Tsukui S, Tane M, Ishimaru M, Suzuki T, \& Nakajima H, Diffusion of oxygen in amorphous $\mathrm{Al}_{2} \mathrm{O}_{3}, \mathrm{Ta}_{2} \mathrm{O}_{5}$, and $\mathrm{Nb}_{2} \mathrm{O}_{5}, J A P$ 116, 033504 (2014). 14. Nabatame T, Yasuda T, Nishizawa M, Ikeda M, HorikawaT, Toriumi A, Comparative Studies on Oxygen Diffusion Coefficients for Amorphous and $\mathrm{Al}_{2} \mathrm{O}_{3}$ Films using ${ }^{18} \mathrm{O}$ Isotope, Jpn. J. Appl. Phys. 42, 7205-7208 (2003).

15. Philibert J, Atom Movements. Diffusion and Mass Transport in Solids, Les Edition des Physiques, 1991

16. Crank J, The Mathematics of Diffusion, Oxford University Press, 1975

17. Tanuma S, Powell C.J, Penn D.R, Calculations of electron inelastic mean free paths for 31 materials. Surf. Inter. Anal. 11, 577-589 (1988).

18. Menyhard M, High-depth-resolution Auger depth profiling/atomic mixing, Micron 30, 255-265 (1999).

19. Zommer L, Jablonski A, Kotis L, Safran G, Menyhard M, Simulation and measurement of AES depth profiles; a case study of the C/Ta/C/Si system, Surf. Sci. 604, 633-640 (2010). 
Figures

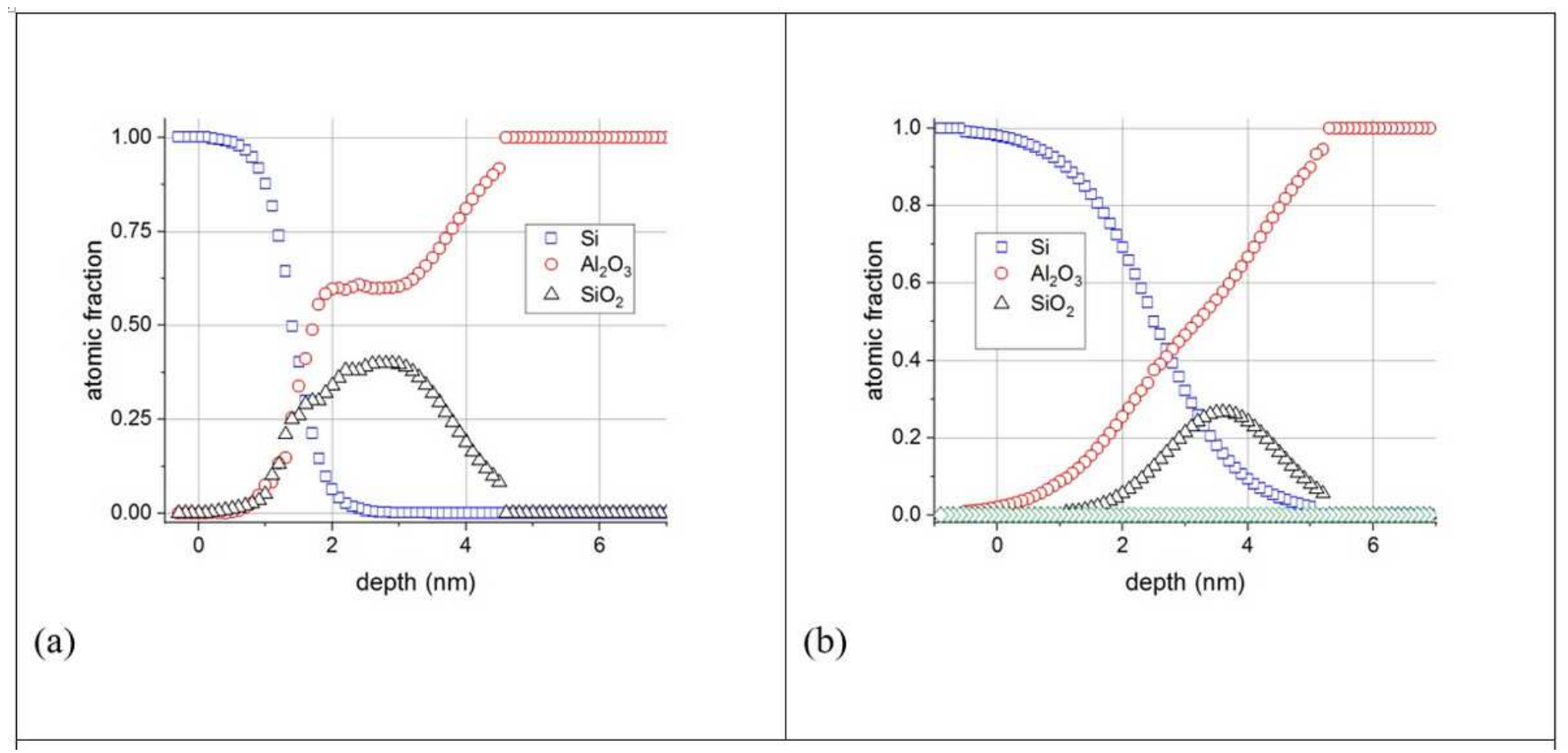

Figure 1

Concentration distributions after electron irradiation at room temperature of $5 \mathrm{keV}, \mathrm{l}=500 \mathrm{nA}, 21 \mathrm{~h}$ for samples (a) $5 \mathrm{~nm} \mathrm{Al203/Si} \mathrm{and} \mathrm{(b)} 20 \mathrm{~nm} \mathrm{Al203/Si} \mathrm{(the} \mathrm{non-altered} \mathrm{part} \mathrm{of} \mathrm{the} \mathrm{sample} \mathrm{is} \mathrm{not} \mathrm{shown).}$ The position of the original Al203/Si interface is at $0 \mathrm{~nm}$, the positive direction is toward the layer. The denotations $\mathrm{Si}, \mathrm{Al} 2 \mathrm{O} 3$, and $\mathrm{SiO} 2$ in the legend stand for pure $\mathrm{Al2O}$, (metallic) Si, and $\mathrm{SiO} 2$, respectively. 


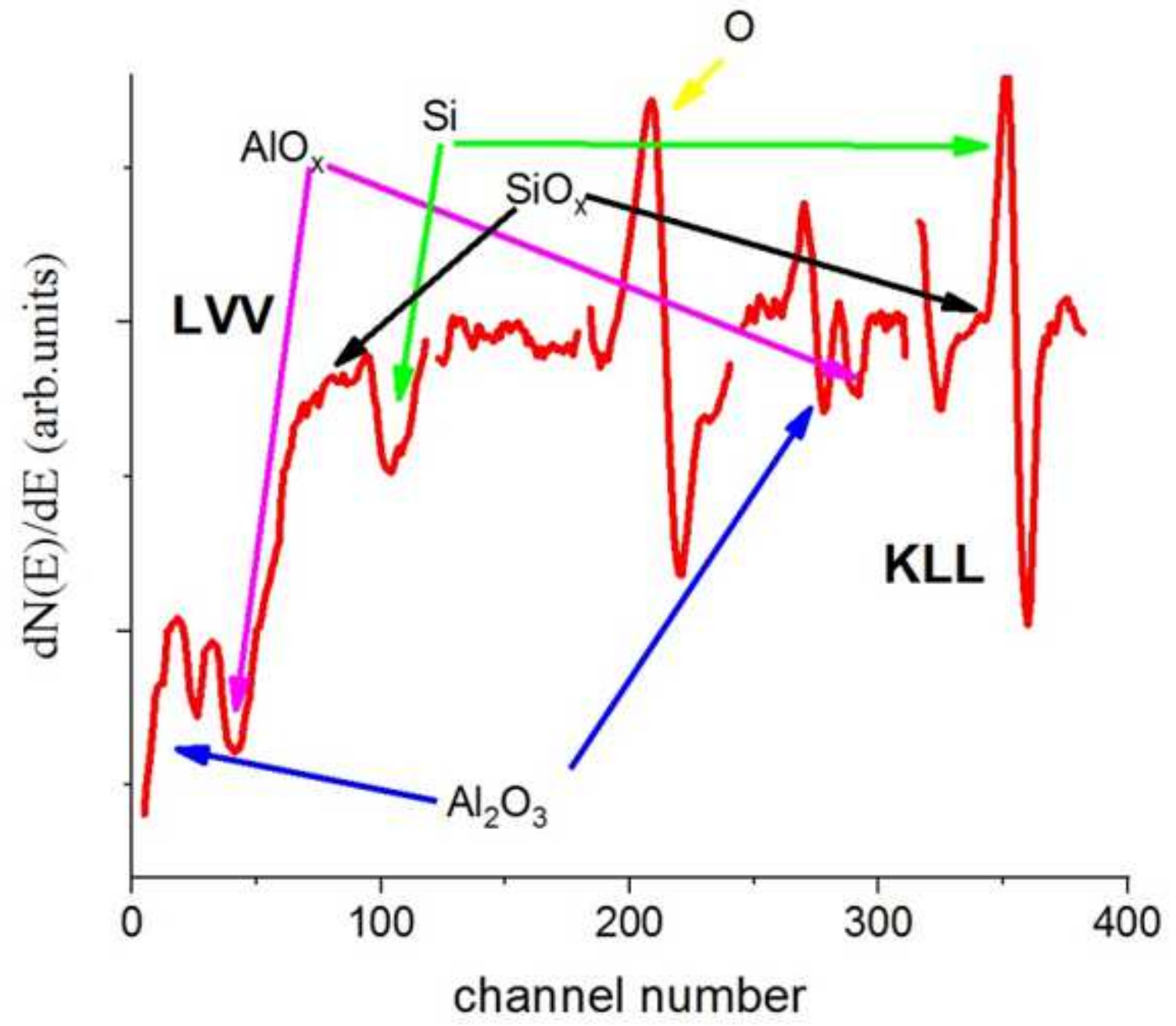

Figure 2

The differentiated, $N(E)^{\prime}$, Auger electron spectrum of $5 \mathrm{~nm}$ Al203/Si substrate sample recorded in a depth of $3.2 \mathrm{~nm}$ (measured from the free surface) after the irradiation of $500 \mathrm{nA}$ and $16 \mathrm{~h}$. The temperature of the sample during irradiation was 500o C. AlOx and SiOx stand for Al and Si suboxide (see also the text), respectively. On the figure the peaks belonging to LVV and KLL transitions are signed. 


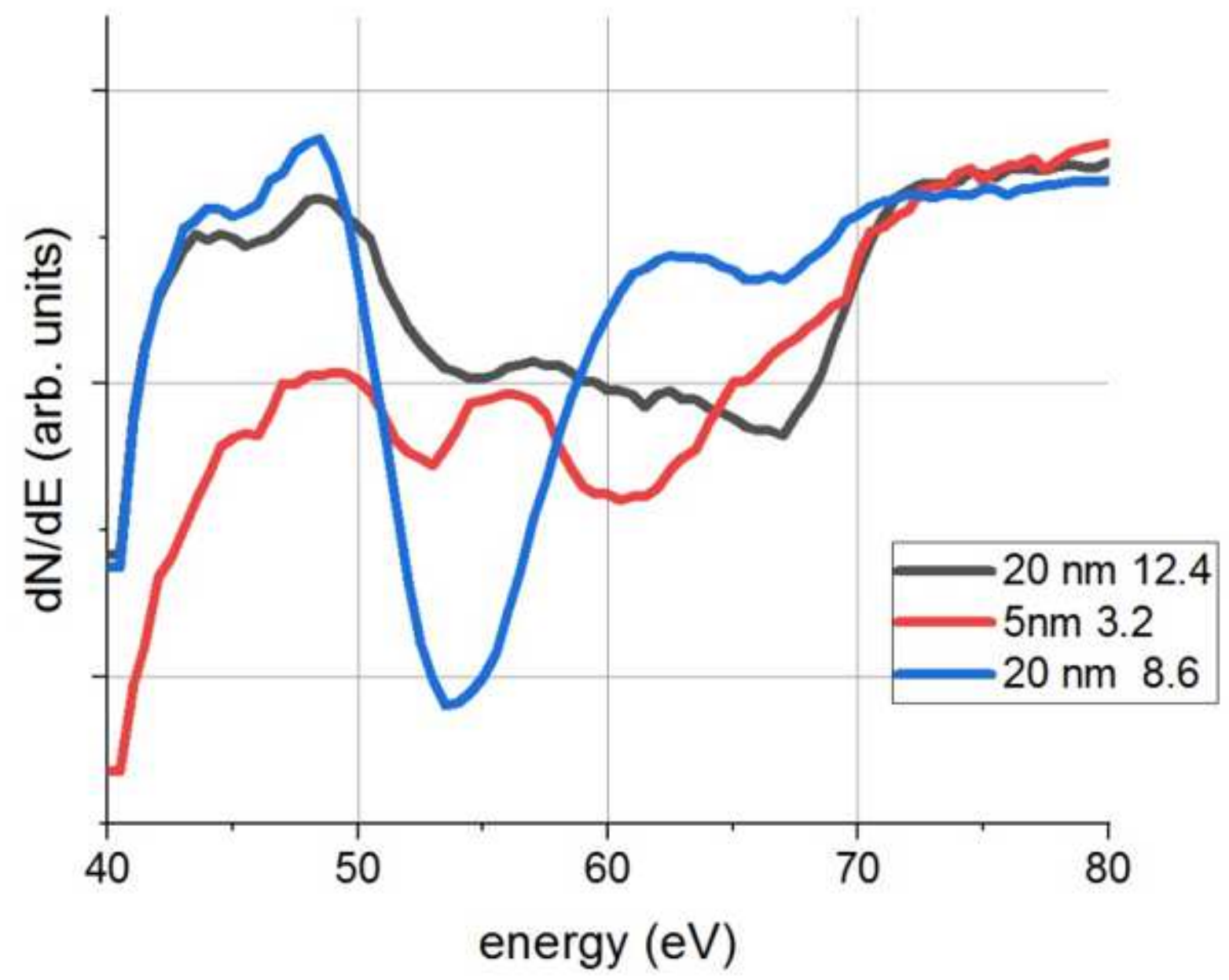

Figure 3

AlLLV lines in various depths (measured from the free surface) and samples (with $20 \mathrm{~nm}$ and $5 \mathrm{~nm}$ thick Al203 layers, resp.); the last number in the legend gives the depth (in $\mathrm{nm}$, measured from the free surface) of the region providing the Auger line. 


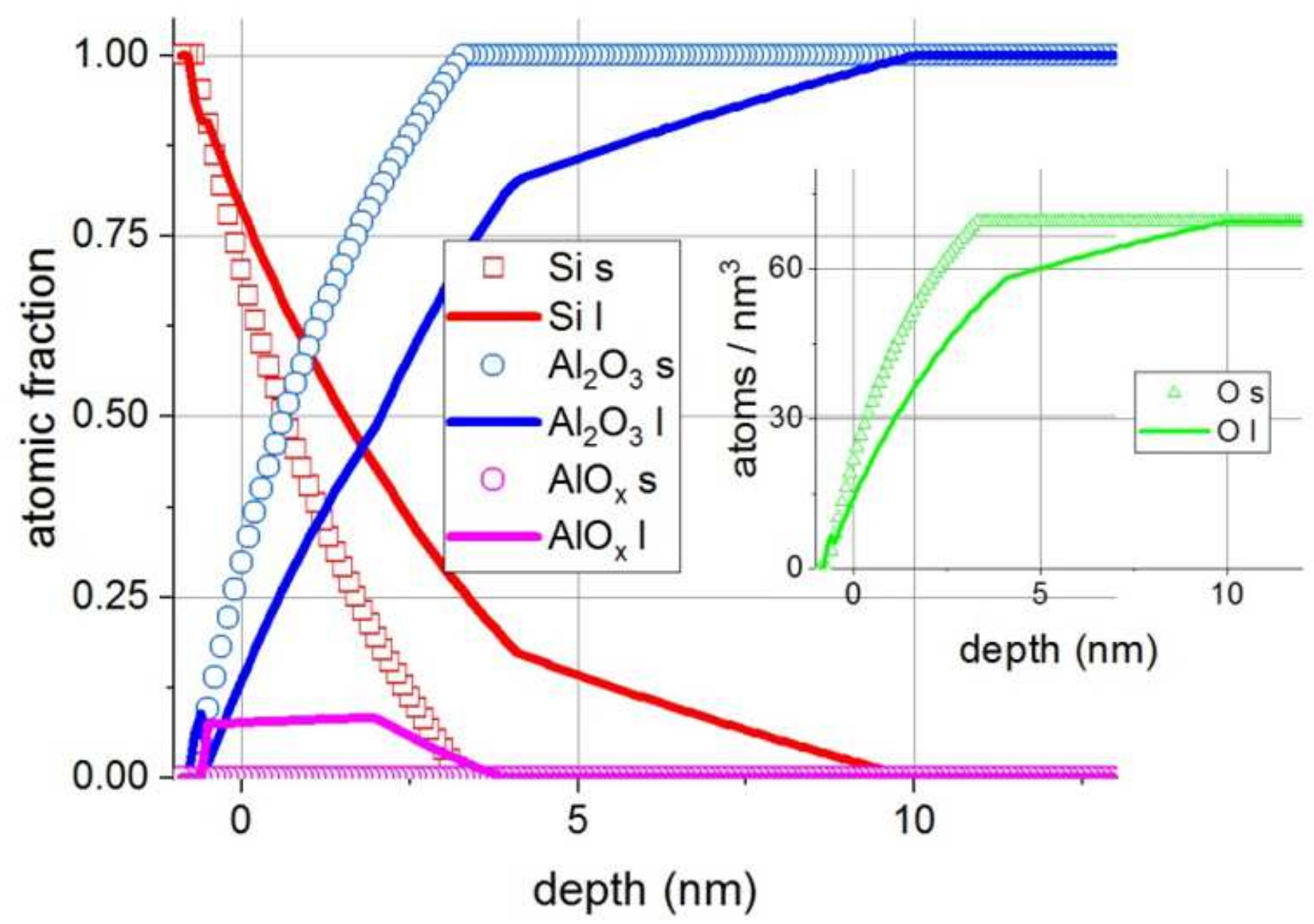

Figure 4

Depth profiles of $20 \mathrm{~nm}$ Al203/Si substrate samples irradiated by Q (denoted by s in the legend) and $2 \mathrm{Q}$ (denoted by I in the legend) electron dose; sample temperature is $500 \mathrm{oC}$. The position of the original Al203/Si interface is at $0 \mathrm{~nm}$, the positive direction is toward the layer (for clarity only the altered part is shown). The insert shows the 0 depth profile in atoms $/ \mathrm{nm} 3$ units. 


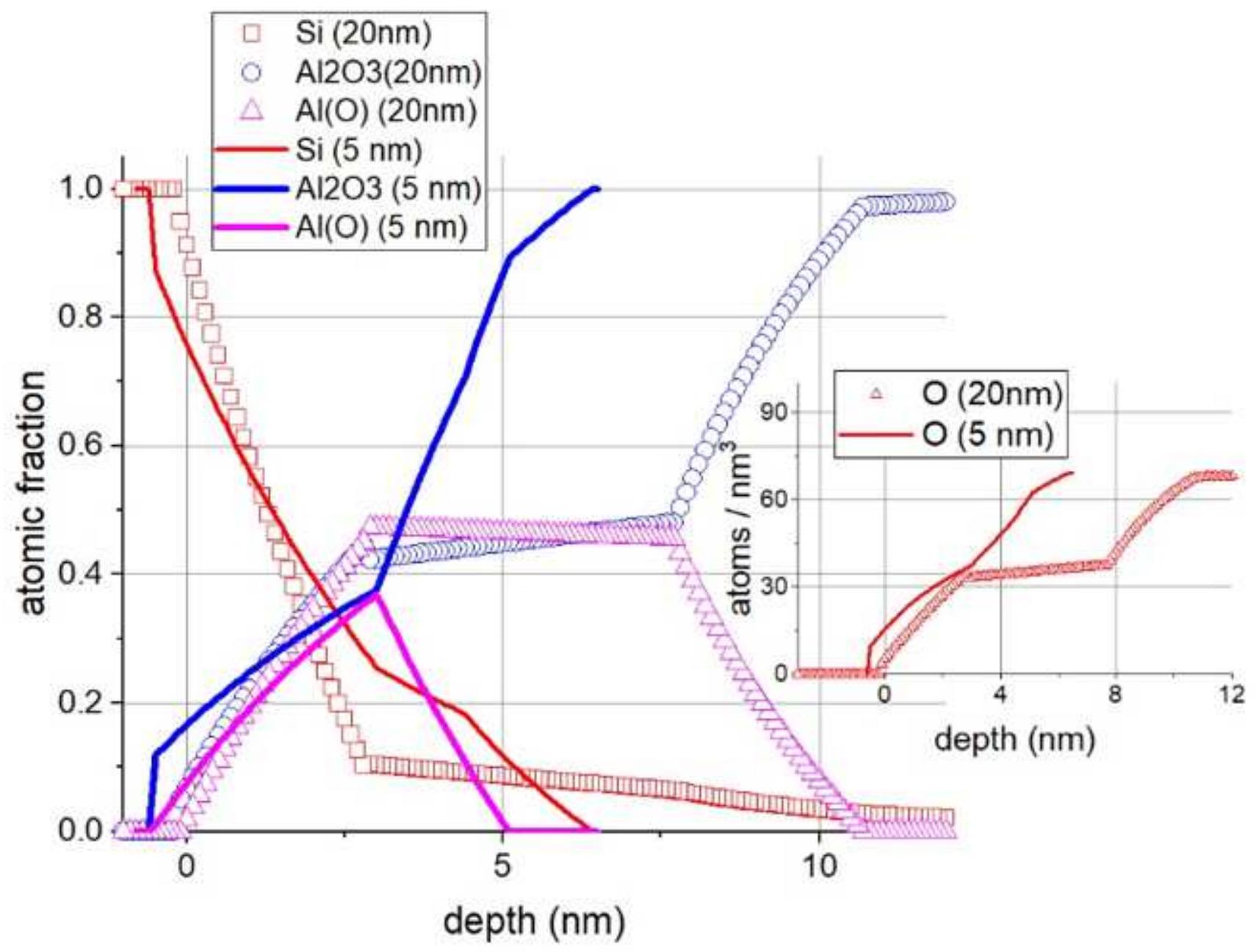

Figure 5

The concentration distributions after electron irradiation at 500 oC of samples $5 \mathrm{~nm}$ and $20 \mathrm{~nm} \mathrm{Al203/Si}$ substrate. The position of the original Al2O3/Si interface is at $0 \mathrm{~nm}$, the positive direction is toward the layer (for clarity only the altered part is shown). The denotations Al203, Si, AlOx in the legend stand for pure Al203, metallic Si and Al suboxide, respectively. The insert shows the 0 depth profile in atoms/nm3 units. 


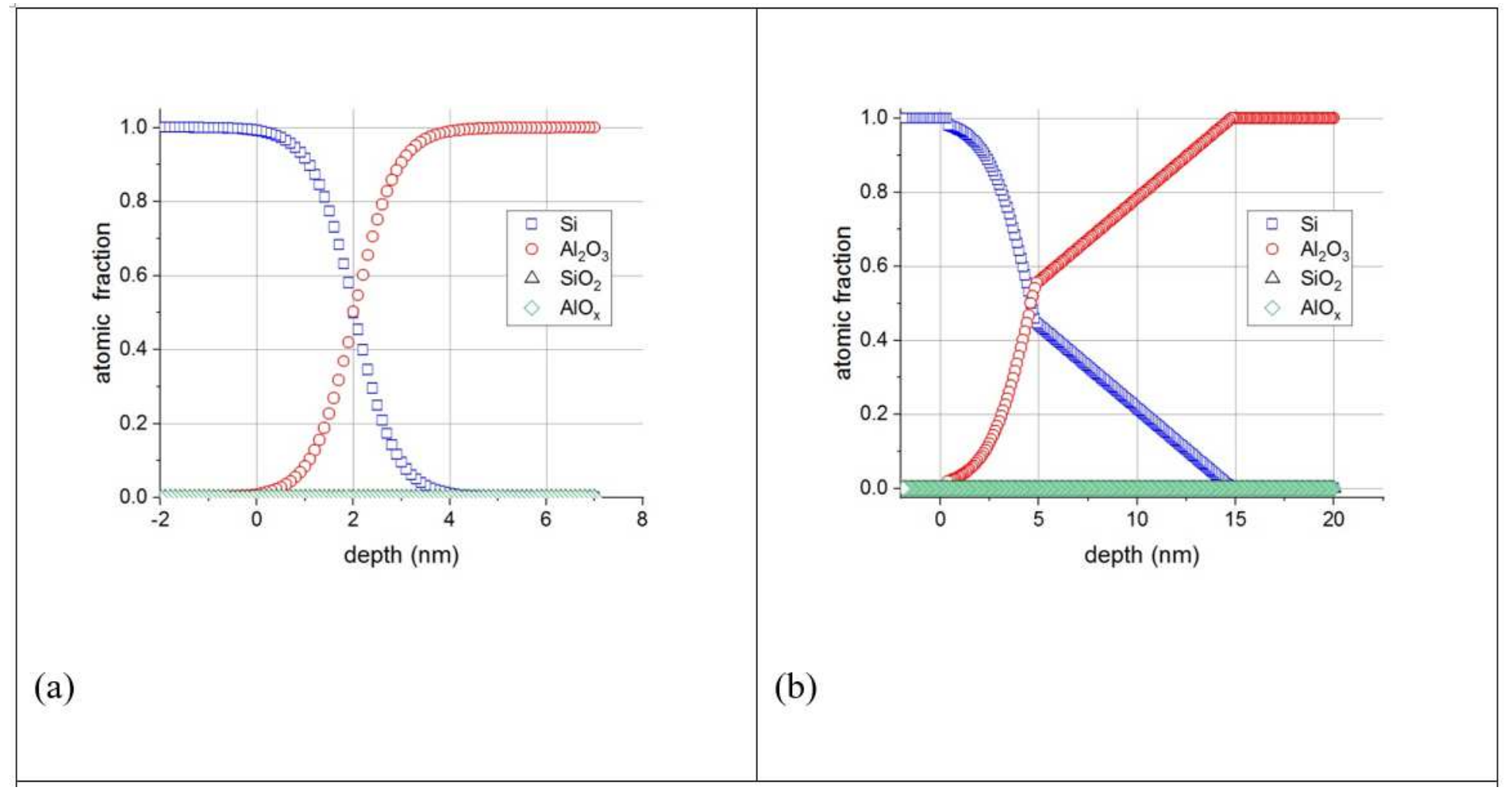

Figure 6

Concentration distributions after electron irradiation at $7000 \mathrm{C}$ of sample (a) $5 \mathrm{~nm}$ Al203/Si substrate and (b) $20 \mathrm{~nm} \mathrm{Al203/Si} \mathrm{substrate.} \mathrm{The} \mathrm{position} \mathrm{of} \mathrm{the} \mathrm{original} \mathrm{Al203/Si} \mathrm{interface} \mathrm{is} \mathrm{at} 0 \mathrm{~nm}$, the positive direction is toward the layer.

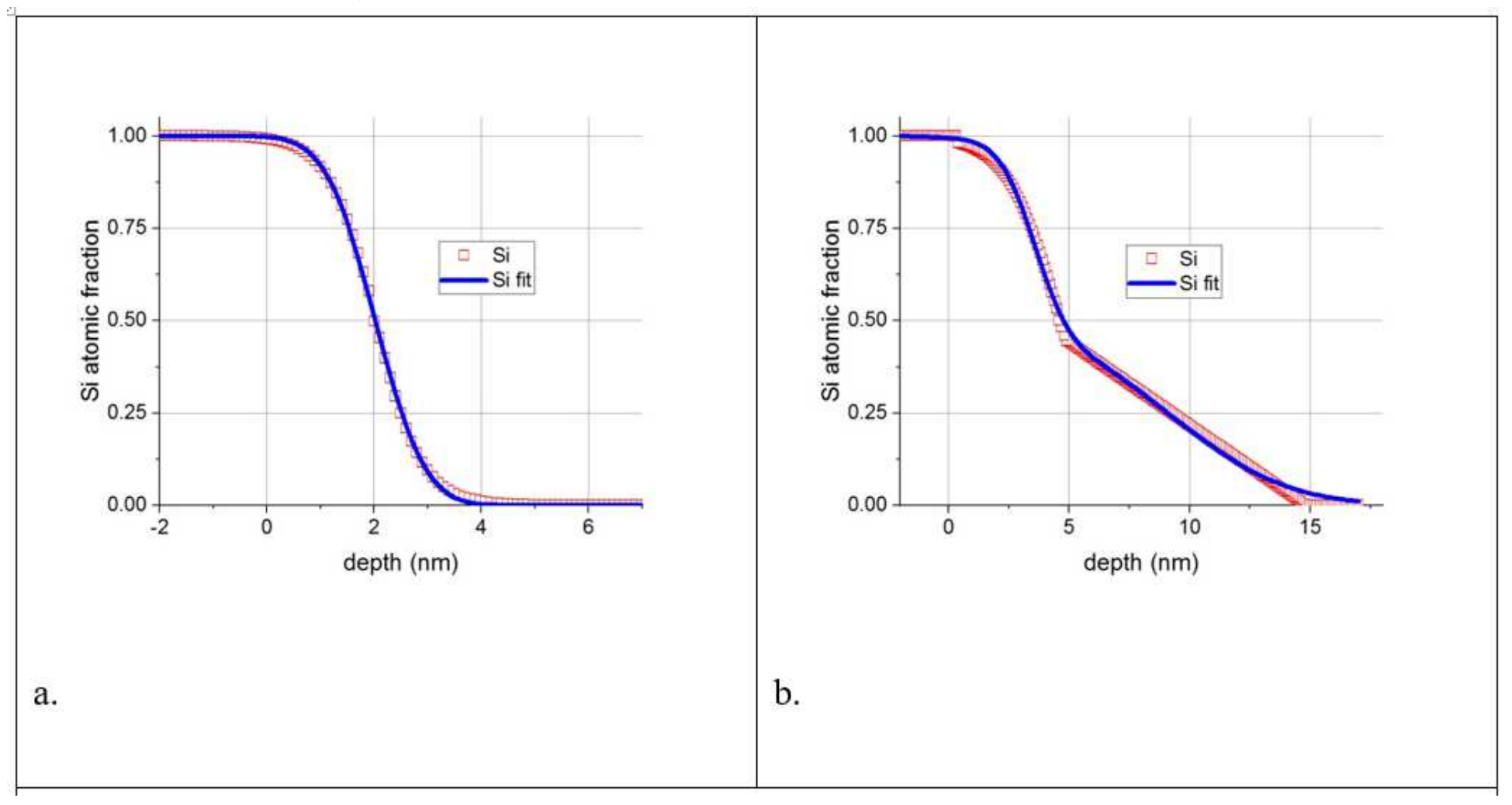

Figure 7 
Fit of the composition profiles by erfc function to deduce the diffusion coefficients, for samples irradiated at 700o C: (a) $5 \mathrm{~nm} \mathrm{Al203/Si} \mathrm{substrate,} \mathrm{(b)} 20 \mathrm{~nm}$ Al203/Si substrate. Solid lines are the fitted curves 